\title{
Study on the Management Mode of PPP Energy Engineering Project from the Perspective of Cooperative Theory
}

\author{
Weihua Yang ${ }^{1}$,Feige Fan $^{2 *}$ and Ling $\mathrm{Li}^{3}$ \\ ${ }^{1}$ School of Management, Dalian Polytechnic University, Dalian, Liaoning, 116034, China \\ ${ }^{2}$ School of Management, Dalian Polytechnic University, Dalian, Liaoning, 116034, China \\ ${ }^{3}$ School of Management, Dalian Polytechnic University, Dalian, Liaoning, 116034, China
}

\begin{abstract}
PPP energy engineering project is related to the life of the people and the development of the country. According to the data disclosed by the Ministry of Finance, the investment scale is huge and the interest subjects involved are complex. How to coordinate many subjects to maximize the overall interests of the project is the main problem at present. In this paper, the collaborative theory can be introduced into PPP energy engineering project management to solve this problem, the present situation of PPP energy project management is discussed, and the dynamic collaborative sharing model is put forward on the basis of vertical life cycle management and horizontal community of destiny management.
\end{abstract}

\section{Introduction}

With China's economy entering the new normal, the people's demand for high-quality energy is increasing day by day. According to the announcement by the Ministry of Finance and the Social Capital Cooperation Center, the number of energy engineering projects in storage has increased to 122 as of August 31, 2019, including 20 provincial demonstration projects and 22 national demonstration projects. PPP project management model includes project financing mode, project organization model and project delivery mode[1]. At present, BOT (Build-Operate-Transfer) financing mode is the most commonly used in PPP energy projects. There are many problems in the process of project implementation and management, such as non-agile tissue response, unobtrusive core competence, High risk, high cost, and easy to produce the information isolated island and so on. The traditional collectivized structure model has become more and more unable to adapt to the rapidly changing market demand. Matrix and dynamic alliance project organization structure is relatively suitable for modern project management needs, resources can be shared in multiple projects, improve the utilization of resources. Each project department pursues its own goal, not the overall goal of the engineering project, which makes it difficult to achieve goal one.

Therefore, it is necessary to draw lessons from the advanced management mode, integrate the industry advantage resources across fields, further explore the PPP energy project management mode, and improve the project management performance. This paper discusses the present situation of PPP energy project management mode, and probes into the dynamic collaborative sharing mode based on collaborative theory.

\section{Agreement Analysis between Synergetic Theory and PPP Project}

German scientist Harken founded the Synergetic Theory in the 1970s, which holds that the overall utility of collaborative operation between the elements of the system through conscious behavior integration is greater than that of the sum of each part2. Collaborative theory has been applied in the field of management science and applied science, such as economic development in economics3, social change in sociology and so on 4 , but there are few applied research in the field of governmententerprise cooperation. PPP energy engineering project is a complex open system involving many stakeholders. On the whole, the relationship between different types of PPP project stakeholders leads to complexity. In the process of PPP project implementation, each subject must exchange resources and information in the whole environment in order to achieve its own project objectives.Within the project, there are institutional constraints among the stakeholders of PPP project, and the convergence and communication of the processes of each stage of the project constitute a complex nonlinear relationship between the various subjects. At present, in the process of implementing PPP energy engineering project in China, the allocation of power, responsibility and profit is not clear enough, and the institutional environment is not yet mature, a long-term stable and orderly management mode has not yet been formed.

Academic research on PPP project stakeholders has continued to deepen and expand, but scholars' research is mostly at the stakeholder level, and there are few related researches on collaborative sharing management models. Ye Xiaosu and others studied how the interest 
relationship, factor analysis and distribution methods in PPP project cooperation promote effective cooperation and coordination between the two parties, and achieve balanced governance of all stakeholders5. Yang Wenyu believes that there are many PPP projects and the parties form a complex network organization structure involving major participants and contractual relationships6. Gao Shaochong and Ding Ronggui researched project governance based on social network analysis7. Ren Zhitao believes that the PPP model is an equal network structure8. It is proposed that the characteristics of PPP network stakeholders are mainly complex, dynamic, oriented and informatized. It is considered that there is not a simple linear relationship between project organization and synergy. There is no natural synergy capability. In order to ensure the smooth implementation of the project, all stakeholders must strengthen communication and achieve timely sharing of project information.Therefore, it is very important for PPP project management to be clarified in order to clarify the accrual configuration of each benefit subject and to construct the management mode corresponding to it.

\section{Construction of PPP energy project structure model}

The PPP energy project management model from the perspective of synergy theory is a joint project organization or project implementation enterprise to unite the objectives of the entire project, reduce project risks and improve the market position of the project. Among them, each project is independent but interoperable, mutually cooperative, and mutually committed, so that the projects of all parties are completed with the lowest cost, the shortest time, the highest owner satisfaction and reliable market guarantee. It is a model in which various government departments and the private sector work together to achieve multi-win results.

\subsection{PPP Energy Project Relational subject}

The relationship between the government department and the private sector in the energy project is the premise of adopting the PPP model. The concept of "collaboration and win-win" is the concept of risk sharing and revenue sharing in the project, which encourages stakeholders to give full play to their advantages. The main relationship of PPP energy project is shown in Figure 1.

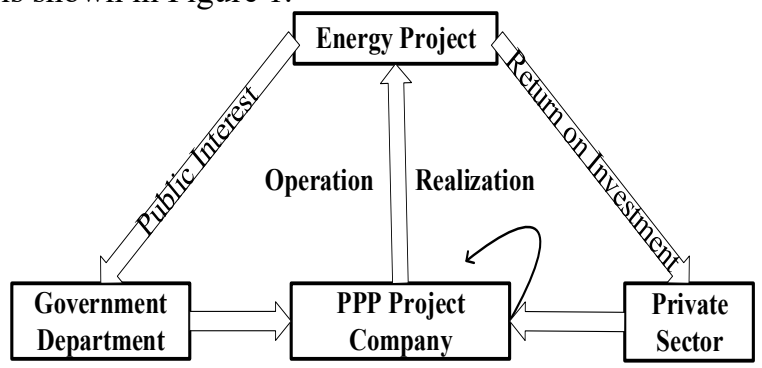

Figure 1. PPP main body relationship of Energy Project

\subsection{Vertical Life cycle Management}

According to the American Project Management Association, the project life cycle is a series of stages that go through from beginning to end. From the perspective of the construction project phase, it mainly includes the preliminary planning phase, the design phase, the construction phase, the completion acceptance handover phase, and the operation and maintenance phase. In PPP mode, projects are mainly divided into identification, preparation, procurement, execution and handover phases. The energy project is combined with the BOT to divide the life cycle of the energy project into a tendering phase, a construction phase, an operation phase and a transfer phase. Vertical lifecycle management can adopt dynamic process management and control from macro to micro of PPP projects to enhance the emergency response capability of the project at different stages, reduce unnecessary risk losses, save project costs, improve project utilization, achieve project risk identification and pre-control.Figure 2 shows the life cycle of the project

The bidding phase is a key part of the PPP project, including the preliminary preparation of the project, and evaluates the environmental benefits, social benefits and economic benefits. After completing the project design plan, it is reported to the competent department for the application result. The relevant government departments will invite bids for the projects approved and select the most suitable companies from many bidding companies for cooperation. The investor is determined through bidding to form a franchise contract relationship, and the two parties conduct in-depth discussions on the specific matters of the project.

The construction phase is that the private sector of the PPP project obtains the franchise right and forms a construction contract with the construction company. This stage involves material suppliers, insurance companies, construction subcontractors, etc. The construction company needs to follow the design plan provided by the design company. The design company also needs to be responsible for the guidance and correction work in the project construction process. When the design plan is affected by special reasons, all relevant parties need to negotiate and adjust the design plan in time to ensure the efficiency and quality of the project.

The operation phase refers to the construction company and the operating company to reach a service contract. The operating company is mainly responsible for equipment management, product supply and maintenance, and supervision of the overall operation stage. The Ministry of Finance stipulates that the cooperation period for government and social capital cooperation projects using the BOT model is generally 20-30 years, and the maximum period is no more than 30 years. The project cycle is long, and the project uses many customers, which will generate huge data information. Therefore, at this stage, Internet + technology must be used to strengthen information management and improve operational management capabilities. 
During the transition phase, after the end of the franchise period, the private sector handed over all fixed assets, rights, documents, materials and files to the government. Relevant government departments need to supervise and review the handover plans and materials, and carry out overall project performance evaluation, summarizing project experience and deficiencies, in order to continuously improve the efficiency of PPP projects.

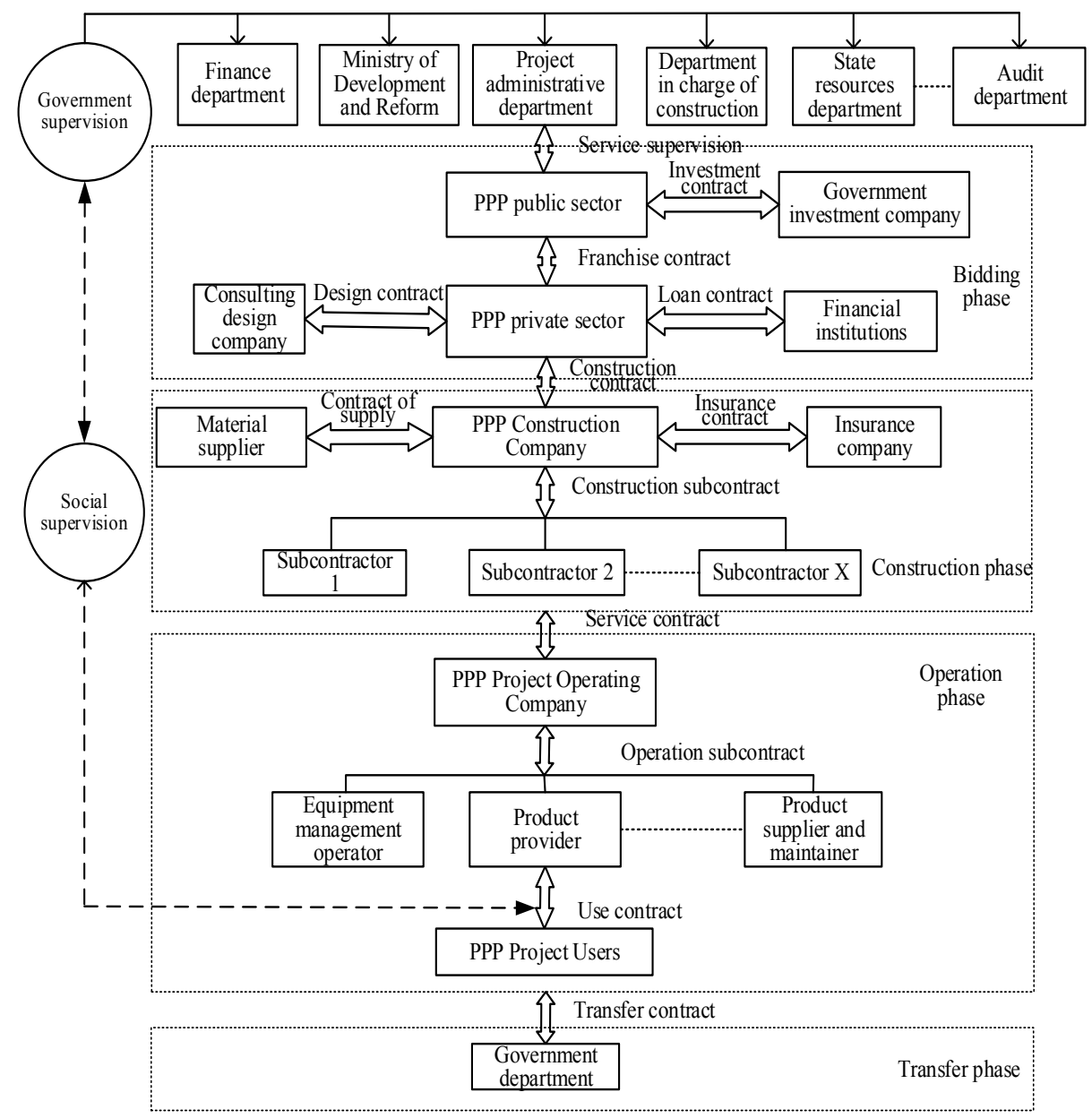

Figure 2. PPP Energy Project structure Diagram

\subsection{Community management with a shared future based on horizontal management}

As shown in Figure 2, in the construction phase, horizontal fate community management refers to the core construction company in the daily project construction, through the control of information flow, capital flow and logistics, from the supply contract of purchasing raw materials to the insurance of insurance companies. The contract formed a community of destiny with a construction company as its core. In this community, "win-win" thinking is very important, and the implementation of each decision of the relevant parties will cause the butterfly effect. Therefore, each participant should consider the maximization of their own interests while ensuring the basic interests and profit bottom line of other companies. This greatly reduces the project construction cost and ensures the quality of the project.

\section{Dynamic Cooperative Management platform of PPP Energy Project}

The project dynamic collaborative management platform should focus on project management and share information technology resources to establish a shared pool platform for multi-level entities. In this shared pool, users can instantly input real-time output and projectrelated information to reduce the deferral rate of resource transmission and reach the fast operation of the project. It is mainly constructed from the following four levels: the construction of dynamic collaborative platform for government departments, real-time monitoring of various stages of the project, multi-dimensional communication with the participants, and real-time feedback to promote the steady development of the project. The construction of dynamic collaborative platform for owners, supervision companies and consulting design achieves real-time informationization and visualization, and provides the ultimate solution for the project. Facing the 
construction of a collaborative platform at the construction and operation company level, using multiterminal access to feedback the on-site status of frontline workers. The collaborative platform for the public to provide customers with a platform to experience products and feedback, improve service quality, achieve information sharing, and reduce communication costs.

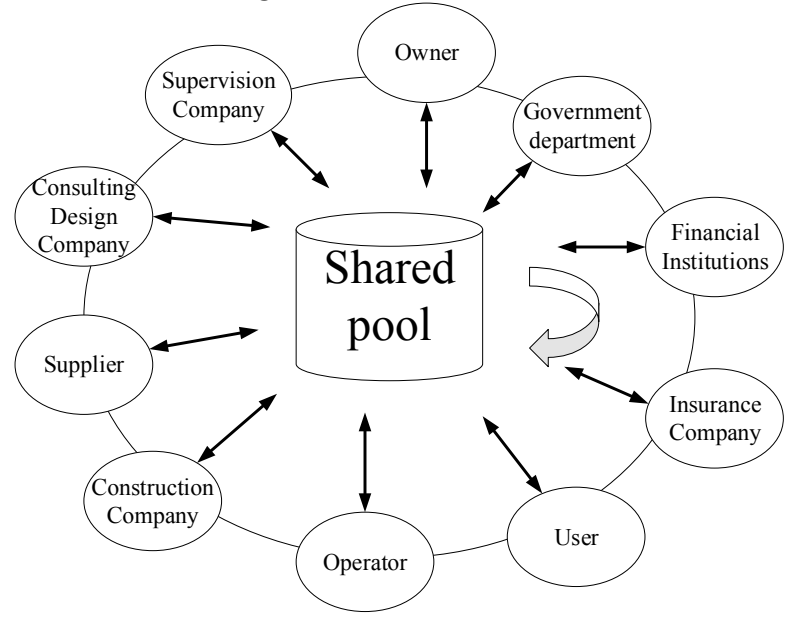

Figure 3. Framework of dynamic collaborative management platform for each principal

\section{Conclusion}

The successful application of the project dynamic collaborative sharing model in energy engineering management needs to be supported by the following key elements. The first is the high degree of consistency of the objectives; the second is the corresponding organizational structure and human resources allocation; the third is sufficient trust; the fourth is advanced network technology; the fifth is the smooth implementation process. The establishment of a dynamic collaborative management platform is a complex project that requires cross-professional research in different fields, and is inseparable from the support of computer technology. In the process of energy engineering project management, it can break through organizational boundaries, eliminate information islands, and realize information.

\section{Acknowledgement}

The research was awarded the National Natural Science Foundation Youth Fund Project and Key Projects of Liaoning Social Science Planning Fund: Research on Implementation Mechanism, Diffusion Path and Related Policies of Simple Innovation for Small and Micro Enterprises in Chinese Context (Project No.: 71802035).Research on Technological Innovation and Productivity Improvement of Real Economy from the Perspective of Financialization (Project No.: 71703012).Research on PPP Model Selection and Supporting Policies for Social Pension in Liaoning Province (Project No.: L16AGL003).Liaoning Province Socialized Pension PPP Mode Selection and Support Policy Research, 2016 Liaoning Provincial Social
Science Planning Fund Key Project (Project No: L16AGL003).

\section{References}

1. Ma Zhiliang, Li Songyang. (2018) A new project management model under the "Internet +" environment. J. Journal of Tongji University(Natural Science).,46: 991-995.

2. Xiao Hua. (2019) Research on Emergency Resource Disposal Information Resource Sharing from the Perspective of Synergy Theory. J.Journal of Modern Information.,39:109-114.

3. Xu Yingnan. (2019) Reconstruction of Rural Ecommerce Accurate Poverty Alleviation Path under Rural Revitalization Strategy_-Based on Synergetic Theory.J.Journal of Commercial Economics.,771:80-83.

4. Zhang Mingzhe, Zhang Jingxiang, He Heming.(2019)Research on the Formation Mechanism of Urban Massive Space Cluster Based on Synergetic Theory-Taking Hangzhou City as an Example. J.Urban Development Studies.,26:2936.

5. Ye Xiaosu, Wu Shuxia, Shan Xueqin.(2010) Study on the Interest Relationship and Distribution in PPP Project Cooperation in China . J. Science \& Technology Progress and Policy., 27:36-39.

6. YANG Wenyu.(2010) Analysis of the Whole Life Cycle Dynamic Risk Management of Infrastructure PPP Projects. J.Project Management Technology.,08:39-43.

7. Gao Shaochong, Ding Ronggui, Zuo Jian. (2018) Research on Risk Evaluation and Strategy of Government and Enterprise Cooperation (PPP) Project Governance-- Based on Social Network (SNA) Method. J. Journal of Engineering Management., 32: 126-131 .

8. Ren Zhitao, Wei Chang. (2019) Research on the Evaluation of Resilience of Symbiosis Network in PPP Mode of Smart Governance.J. Science and Management., 39: 87-93. 